\title{
PQ2019: Diretrizes para o espaço e desenho da cena contemporânea
}

\author{
Aby Cohen \\ Universidade de São Paulo - USP, São Paulo/SP, Brasil \\ E-mail: abycohen.br@gmail.com
}

\section{Resumo}

A Quadrienal de Praga como principal evento do espaço e desenho da cena, anteriormente cenografia e arquitetura cênica, tem fundamental papel na cena contemporânea como catalisador das influências e referências globais neste campo, bem como impulsionador de reflexões e tendências. A PQ é aqui comparada à Dokumenta de Kassel, respeitados os respectivos contextos das artes cênicas e das artes visuais, em consequência de sua transformação - a partir de 2007 - que culmina no seu reconhecimento, em 2015, como um dos doze mais importantes Festivais Europeus de Arte. Diante desta trajetória e responsabilidade em apontar diretrizes, faz-se relevante analisar para onde aponta a $14^{a}$ edição da Quadrienal de Praga - PQ2019. Ainda, neste contexto, como a participação do Brasil dialoga e colabora com a continuidade de reflexões e transformações provocadoras nos modos de produção e exposição do espaço e desenho da cena.

\section{Palavras-chave}

Cenografia. Curadoria. Desenho da Cena.

Quadrienal de Praga. PQ2019.
The Prague Quadrennial as the main event of space and design for performance, formerly scenography and scenic architecture, has fundamental role in the contemporary scene as a catalyst of influences and global references on this field, as well as an exponent of trending in practice and studies. $P Q$ is comparable to the Dokumenta of Kassel, respecting the respective contexts of Theatre, Performing and Visual Arts, in consequence of its transformation, from 2007, which culminates in its recognition, in 2015, as one of the twelve most important European Arts Festivals. In view of PQ's trajectory and responsibility in pointing out guidelines, it seems relevant to analyse the 14th edition of the Prague QuadrienalPQ2019 on where it leads us. Also, in this context, how the Brazil's participation dialogues and collaborates with the continuity of provocative reflexions and transformations about the methods of creating and presenting the space and design for performance. Keywords

Set Design. Curatorship. Performance Design. Prague Quadrennial. PQ2019. 


\section{A trajetória de transformação} da Quadrienal de Praga: 2007-2015

A Quadrienal de Praga (PQ'), desde sua fundação, em 1967, caracteriza-se como lugar de confluência mundial para os artistas, arquitetos e técnicos teatrais com foco no espaço e desenho da cena.

Hoje denominada simplesmente Quadrienal de Praga, teve seu título modificado de Quadrienal de Praga de Cenografia e Arquitetura Teatral ${ }^{1}$ para Quadrienal de Praga do Espaço e Desenho da Cena; registro este difícil hoje de encontrar nos arquivos digitais relativos ao evento, mas importante registrar e evidenciar para as questões aqui apresentadas.

Tratar sobre a $14^{a}$ edição da Quadrienal de Praga 2019 convida a referenciar relevantes aspectos relacionados a edições prévias que modelam e estruturam a PQ e seu papel na atualidade, além de subsidiar o pensamento e análise crítica sobre como esta mais recente edição, realizada de 6 a 16 de junho de 2019, se apresenta e as diretrizes para qual aponta no campo da prática e dos estudos sobre o espaço e desenho da cena.

A partir da sua $11^{\text {a }}$ edição, em 2007 , a Quadrienal de Praga passa por transformações que buscam, de forma mais constante e utilizando os intervalos de quatro anos entre o acontecimento da $P Q$, debater e refletir sobre as inquietudes dos artistas da cena e as abordagens contemporâneas da cenografia, para além de apresentá-la. É neste momento que a $P Q$ passa a afirmar-se como um lugar de referência do espaço e desenho da cena, assim como a Dokumenta de Kassel ${ }^{3}$ existe para as artes visuais.

1 Prague Quadrennial of Stage Design and Theatre Architecture - título original em inglês, traduzido para: Quadrienal de Praga de Cenografia e Arquitetura Teatral.

2 Prague Quadrennial of Performance Design and Space - título original em inglês lançado em 2011 e traduzido para o português, pela curadoria do Brasil em 2019 como: Quadrienal de Praga do Espaço e Desenho da Cena - termo este utilizado neste artigo.

3 A Dokumenta de Kassel é a mostra internacional de referência para as Artes Visuais que acontece a cada cinco anos, em Kassel, na Alemanha.
A transformadora PQ2007, sob a direção artística de Arnold Aronson ${ }^{4}$ - nesta edição assistido por Sodja Lotker ${ }^{5}$, membro de sua equipe e que mais tarde dá continuidade a estas importantes transformações - desafia os curadores a refletirem criticamente sobre as possibilidades e formas de validação ao expor cenografia, apontando para o diálogo entre o concreto e o efêmero, entre o visível e o invisível.

O Teatro tem sido descrito, muitas vezes, como a arte da ausência. O reino visível do palco implica em uma ampla abstração do mundo além. Teatro é estar no palco e nos bastidores - entre o visível e o invisível. [...]. É essa dicotomia da presença e da ausência que dá ao teatro seu poder. Se a PQ' se coloca como performance e define que o salão de exposição é o seu palco e o conteúdo presente é a cenografia, o que está ausente são as performances, às quais se referem as exposições. A PQ' seria meramente uma exposição de objetos fascinantes, mas desprovida de sentido se não existir um diálogo entre o visível e o invisível. (ARONSON; PARIZKOVA, 2008, p. 07, tradução nossa).

Como estímulo à reflexão sobre o papel e lugar da cenografia na atualidade e, consequentemente, colocando em discussão a relevância de um evento do porte da Quadrienal de Praga, a PQ2007 destaca-se essencialmente como marco na sua trajetória, abrindo oportunidades para que curadores e artistas proponham outras formas de apresentação da cenografia e da arquitetura teatral, ampliando inclusive o acesso à participação de curadores e artistas independentes.

4 Arnold Aronson é teórico do teatro. Atualmente leciona na Universidade de Columbia, nos EUA. Foi diretor artístico da $11^{a}$ Quadrienal de Praga, a PQ2007, em 2007.

5 Sodja Lotker foi a diretora artística de duas edições da $P Q$, em 2011 e 2015. 
Em 2011, quando alterada sua denominação para Quadrienal de Praga do Espaço e Desenho da Cena, torna-se ainda mais evidente o desejo em apontar para novas diretrizes. A impossibilidade de retornar ao mesmo edifício que fora sede da $\mathrm{PQ}^{6}$ nas edições anteriores colabora para impulsionar o evento a uma nova perspectiva.

A partir deste momento, a cenografia, como exposição e evento, apartada do acontecimento teatral, ainda que apresentada através de fragmentos vestimentas, objetos, elementos utilizados nos cenários, sons, imagens - está diante de novos desafios, para além de recriar ou estabelecer uma nova composição, mas em afirmar e validar o que é o espaço e desenho da cena na contemporaneidade. Emerge, desta maneira, importante debate e reflexão sobre a cenografia entre a representação e existência mais autônoma, como mero suporte ou como obra em si.

... A representação torna possível a transposição ao objeto real, a realidade objetiva necessita ser precedida de uma realidade subjetiva; nesse sentido, a tarefa do entendimento não é tornar clara a representação de um objeto, mas tornar possível a representação dos objetos. (KANT,1989, p. 207).

A resposta de artistas e curadores participantes da Quadrienal de Praga às ações e propostas curatoriais lançadas pelas edições do evento em 2007 e 2011, endossam, reafirmando definitivamente a $P Q$ como importante espaço de mediação dos diversos pontos de vista e práticas no campo do desenho da cena, culminando em uma edição ainda mais provocadora como apresenta a PQ2015.

Sob o tema SharedSpace: Music, Weather and Politics (Espaço Compartilhado: Musica, Ambiente e Politica), a direção artística $^{7}$ e a equipe

6 O Palácio Industrial Výstaviště, em Praga 7, distante do centro, fora sede da $P Q$ até 2007.

7 Direção artística da PQ2015 conduzida por Sodja Lotker. curatorial $^{8}$ da PQ2015 explora outras possibilidades conceituais e espaciais. Destaca a função social da cenografia no mundo contemporâneo e a relação entre o real e o ficcional, diante da fragmentação dos sistemas, dos modos de leitura e de reconhecimento do mundo no qual vivemos neste momento. A PQ2015 explode assim o espaço e seus limites, deixando de ocupar um espaço convergente e único para fragmentá-lo, fisicamente, em espaços diversos e distintos no coração da cidade de Praga.

\begin{abstract}
A Quadrienal Praga 2015 explora a cenografia como forte e às vezes invisível presença na performance; um poder que nos influencia assim como a música, o ambiente e a política. O teatro é um lugar onde as pessoas se reúnem e onde são estabelecidas importantes relações sócio-políticas. O título SharedSpace aponta para a função social da cenografia, proporcionando um espaço para compartilhar, relacionar e também em conflito (...) A cenografia como uma coreografia constante do imaginário e do real (...) onde nossa capacidade de "ler" a realidade e "escrever" nossas mudanças nele é crítica. (LOTKER, 2015, tradução nossa. Documento eletrônico).
\end{abstract}

A Quadrienal de Praga 2015 obteve êxito em estabelecer tensão e diálogo com a sua localidade e com o mundo, destacando, neste contexto, a relevância do artista do espaço e do desenho da cena, para além de sua produção em exposição, mas como presença, ação e ocupação. Além de apontar para a urgência em refletirmos sobre as formas de compartilhamento e de expansão de fronteiras, nas quais os elementos representativos do desenho e espaço da cena apresentem-se ressig-

8 A equipe curatorial da PQ2015 SharedSpace Music, Weather and Politics, a convite da direção artística, foi formada por: Jiří Heřman (Music), Simon Banham (Weather), Aby Cohen (Politics). e desenho da cena contemporânea

Revista Cena, Porto Alegre, $n^{\circ} 30$, p. 6-16 jan./abr. 2020

Disponível em: http://seer.ufrgs.br/cena 
nificados e potencializados em uma nova proposta, no lugar de apenas referenciar ou representar um evento ocorrido em um outro espaço-tempo; considerando o espaço-tempo aquele agora, em Praga.

A partir deste momento, a Quadrienal de Praga definitivamente deixa de ser um lugar apenas de representação e exposição; aclamada e condecorada como um dos doze mais importantes festivais culturais e de tendência na Europa, pelo prestigiado prêmio EFFE 9 .

A 14ª edição da PQ2019, sob nova direção artística e equipe, consequentemente ao sucesso e construção nas edições anteriores, lida com significativos desafios. Desafios e reponsabilidades de caráter conceitual, espacial e, sobretudo, político ao propor uma continuidade (ou descontinuidade) com as propostas das equipes anteriores em destacar o papel sócio-político dos artistas do campo do desenho da cena no mundo contemporâneo.

À luz da trajetória de transformação da Quadrienal de Praga na virada do século XXI, convidase a refletir sobre como a PQ2019 desafiou curadores, artistas, educadores e estudantes a explorar novas possibilidades para uma abordagem do espaço e desenho da cena. Convida ainda a avaliar a eficácia da PQ2019 em estimular novas proposições para além de como expor cenografia e a alimentar o debate sobre questões relevantes, tais como: qual o sentido de expor cenografia? Como a cenografia passa a ser percebida? O que ela se torna quando transposta para além da cena, extraída do evento teatral? Como ela resiste, ou melhor... existe? Qual é o papel da Quadrienal de Praga na cena contemporânea? O que a $P Q$ projeta no mundo sobre o papel do artista que cria no campo do espaço e do desenho da cena?

Sob a perspectiva da vivência desta transformação e da participação nesta recente edição, tendo como responsabilidade a representação do Brasil, a melhor forma de diálogo faz-se através da experiência in loco da proposta curatorial para esta representação.

9 Prêmio EFFE: Europe for Festivals, Festivals for Europe.

\section{- O Brasil na PQ2019: uma proposta para além do espaço e do desenho da cena}

Motivada pela trajetória de transformação da Quadrienal de Praga e a partir da experiência na $P Q$ desde 1995, sobretudo no olhar e participação nas edições da PQ2007, PQ2011 e PQ2015; a curadoria $^{10}$ da participação do Brasil na PQ2019 foca na construção deste lugar social e político, local e global. Procura conduzir um processo, baseado em um sentimento global de impermanência e em consonância com a natureza inquieta do artista. No movimento migratório do indivíduo e do coletivo, almejando significativa ressonância, sobretudo no lugar de origem, no Brasil, entre os artistas e profissionais da área, procura dar continuidade a um trabalho que tem realizado há cerca de 20 anos, dedicado a promover e fomentar o desenvolvimento do espaço e desenho da cena e do lugar dos artistas que atuam neste campo.

A representação do Brasil na PQ2019 vai além de definir parâmetros sobre o olhar e a seleção de produções de destaque do espaço e desenho da cena nacional na contemporaneidade, ou de como apresentar esta produção no evento de 12 dias de duração. A trajetória e experiência na $P Q$, sobretudo nas edições de 2007 a 2015, inspira a construir e solidificar bases internas, antes e depois desta $14^{a}$ edição em 2019. Motiva a busca por renovadas possibilidades para a produção e a reflexão sobre o desenho de cena, como um ponto convergente entre as artes cênicas, visuais e da performance, um campo híbrido e rico para a criação, produção, pesquisa e formação. Consequentemente, a proposta da curadoria para a participação do Brasil na PQ2019 inclui um programa de ações durante toda a preparação para o evento e, também, na transição para

10 A curadoria do Brasil na PQ2019 ficou a cargo de Aby Cohen - que acumula participações na PQ desde 1995, com destaque para 1999 - Curadora e Designer para Mostra Temática do Brasil; PQ2007 Equipe da Scenofest; PQ2011 premiada com Golden Triga pela Mostra Nacional Brasileira; PQ2015 curadora internacional de SharedSpace/ Politics. 
a próxima edição, objetivando esta estruturação.

Na Quadrienal de Praga 2019, o Brasil esteve presente em vários segmentos: Mostra Nacional (Mostra Países e Regiões/ Profissional), Mostra dos Estudantes, Mostra Fragmentos, Site-Specific Performance; Formations, Workshops e Talks. Dentre as renovações propostas, pela primeira vez, a Mostra dos Estudantes (anteriormente denominada Mostra das Escolas) foi concebida pelos estudantes, apresentando-se um caminho produtivo a conduzir nas próximas participações; aos estudantes foi concedido um lugar a partir deste momento que merece ser defendido e ampliado.

Outra renovação está na condução dos preparativos para a Mostra Nacional (Mostra Países e Regiões), através de um processo alinhado com a proposta conceitual, aberto e compartilhado desde o início dos trabalhos, em 2017, com o público e a equipe de colaboradores. Uma condução que visa promover a integração e abertura de espaços para um múltiplo de vozes, talentos, inquietações, proposições e ideias. O processo conta com a realização de eventos públicos regulares, de encontros entre artistas, estudantes e público em geral, de chamadas públicas inclusive para os profissionais; da realização prévia de duas mostras no Brasil, da implementação de projeto de residências artísticas para produção de performances inéditas e ainda, da criação de uma plataforma digital ${ }^{11}$ como lugar de comunicação, registro e memória da participação do Brasil na Quadrienal de Praga.

O projeto de preparação aposta no desejo em estimular a participação de artistas, profissionais e estudantes, no desafio a que venham ao encontro dos também artistas que organizam a participação do Brasil na PQ. Convida a apresentar seus trabalhos e processos criativos através de ações e provocações que colaboram para destacar o contexto de um teatro político.

11 Plataforma digital PQBrasil: https://pqbrasil.org.

\begin{abstract}
A Mostra Nacional Brasileira (Países + Regiões) na PQ2019 não poderia ser apresentada de outra forma, mas como um manifesto político neste palco global que é a $P Q$, destacando questões latentes locais $\mathrm{e}$ globais. Reflete os conflitos migratórios e também o estado de apreensão e incerteza em relação a proposições políticas recentes que impulsionam para um cenário devastador colocando em risco, acima de tudo, o meio-ambiente, os direitos humanos e a subjetividade da Arte. Neste contexto, a Mostra aborda questões substanciais sobre territorialidade e fronteira, chamando a atenção para o espaço do indivíduo no mundo geográfico, político, cultural e social. Enfatiza a existência do ser humano como centro do conflito e os riscos aos quais está exposto.... Aponta para o conflito entre a imobilidade e a urgência em lutar pela nossa existência neste cenário. (COHEN, 2019, p.15).
\end{abstract}

No contexto da PQ2019, a Mostra Nacional (Mostra Países e Regiões) propõe diálogo fundamental com a trajetória transformadora da $P Q$ e parte de uma proposta de reformulação do modo convencional de expor. O espaço expositivo dado de $25 \mathrm{~m}^{2}$ desdobrado, multiplicado, através de ações e formas de ocupação nas quais este território expande e retrai diariamente. Desdobramento este que não está relacionado ao fato de ser um espaço reduzido ou insuficiente, mas que responde conceitualmente ao impasse entre imobilidade e resistência.

Desenhando entre a realidade e a ficção que o Teatro e a Performance nos permitem explorar, os conceitos curatorial e expositivo são combinados, apresentando camadas e formatos distintos em coexistência para encenar o espaço e o desenho da cena como instalação + exposição + performance, destacando a potência 
das poéticas não-textuais do desenho da cena. No impasse entre imobilidade e resistência, apresenta, simultaneamente, a recente produção de artistas selecionados em formato de ARQUIVO e um programa de performances inéditas, de assinatura coletiva, resultado de residências artísticas - Projeto INTERSECÇÕES - conduzidas especialmente para este fim. Na mobilidade de um território expandido, a curadoria explora as possibilidades entre o fixo e o móvel, entre fronteiras visíveis e invisíveis, entre o espaço do indivíduo e do coletivo. A exposição formada por 10 "cavaletes" fixos transforma-se em elemento móvel, a partir da presença e ativação do corpo, tornada ambulante, ao vesti-los em forma de homem-placa (ou homemsanduíche), ativando a exposição, modificando-a.

Para o segmento ARQUIVO foram selecionados 10 trabalhos de artistas e coletivos, nas áreas da cenografia, figurino, iluminação, desenho da performance e espaço da performance, cuja produção data do período de 2014 a 2018. O Projeto INTERSECÇÕES teve a duração de dois anos 2017/2018 e reuniu cerca de 40 artistas, representados em Praga através de um programa de 12 performances, apresentadas diariamente. 0 conteúdo curatorial, eventos realizados, os artistas participantes, as chamadas públicas e os processos de trabalhos realizados estão disponíveis e acessíveis na plataforma digital PQBrasil. Existe ainda um catálogo impresso que compila as mostras e segmentos nos quais o Brasil participou na PQ2019 que estará disponível digitalmente na mesma plataforma a partir de 2020, como lugar e registro de memória.
Figura 1 - Mostra Nacional Brasileira na abertura da PQ2019.

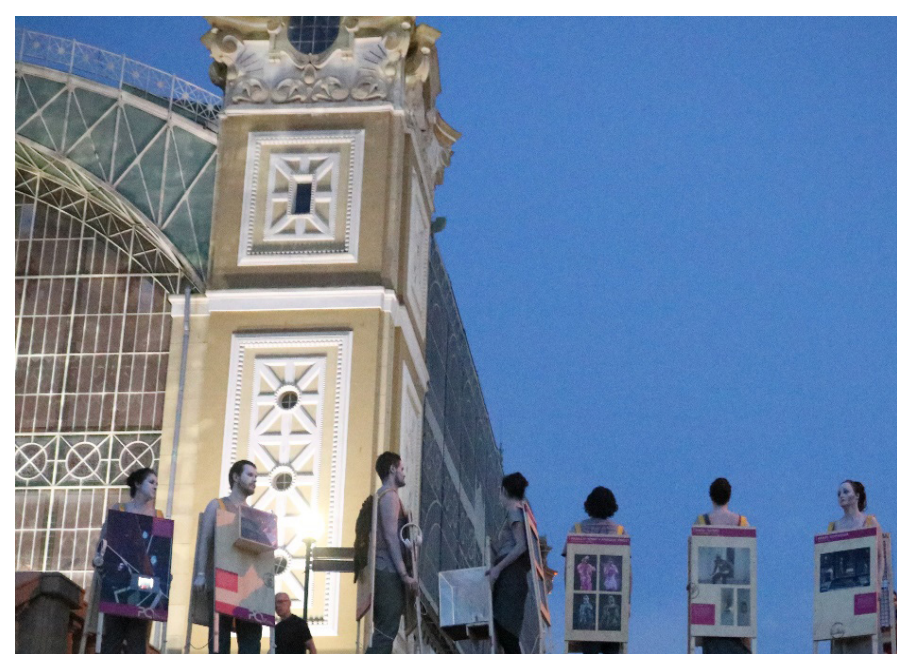

Fonte: Foto de Calen Dawkins (2019).

De forma inédita, uma Mostra Nacional na Quadrienal de Praga é impermanente, transitória, provocando reações diversas ao driblar limites territoriais, seu e de outros. A abertura da Mostra no evento é caracterizada pela impermanência, acontecendo em dois lugares, simultânea e impermanente. Enquanto no Pavilhão $E$ acontece a performance Devastação, a exposição transitória, ambulante conduzida por dez corpos, move-se do Pavilhão $B$, pelo grande Hall até o Pavilhão E para ocupar o espaço da performance finalizada, tornada rastro, parte da composição. Durante os doze dias do evento, o território é constantemente modificado pela ação e presença do corpo. O corpo como presença provocadora, elemento primordial e ativo, rompendo barreiras físicas e psicológicas; corpo como instrumento de resistência, existência e criação.

O CORPO COMO ESPAÇO, TERRITÓRIO E SUAS FRONTEIRAS é o tema curatorial proposto, de autoria desta que aqui escreve, e que emergiu desde os primórdios do processo de desenvolvimento dos trabalhos em 2017. Inicialmente traduz o desejo pelo encontro presencial no qual questões sobre a relevância da $P Q$ e a participação do Brasil no evento foram compartilhados e, inclusive, 
questionados, deixando clara a abertura para uma condução coletiva, na medida em que a presença fosse possível ao longo do processo.

O CORPO COMO ESPAÇO, TERRITÓRIO E SUAS FRONTEIRAS provoca a proposição de espaços e situações para coexistência e negociação, algo já vivenciado como curadora na PQ2015-SharedSpace Politics, quando da criação do projeto No Man's Land. Experiência fundamental para a condução do projeto de curadoria da participação brasileira para a PQ2019, ao retomar as questões relativas a fronteiras, compartilhamento e colaboração, no contexto da $P Q$ e em meio a tantos universos reais e ficcionais ali representados, para evocar questões sócio-políticas locais e globais em ebulição no mundo em que vivemos.

Figuras 2 e 3 - Performance Narciso, por Marcelo D’Ávilla, para a Mostra Nacional do Brasil na PQ2019.
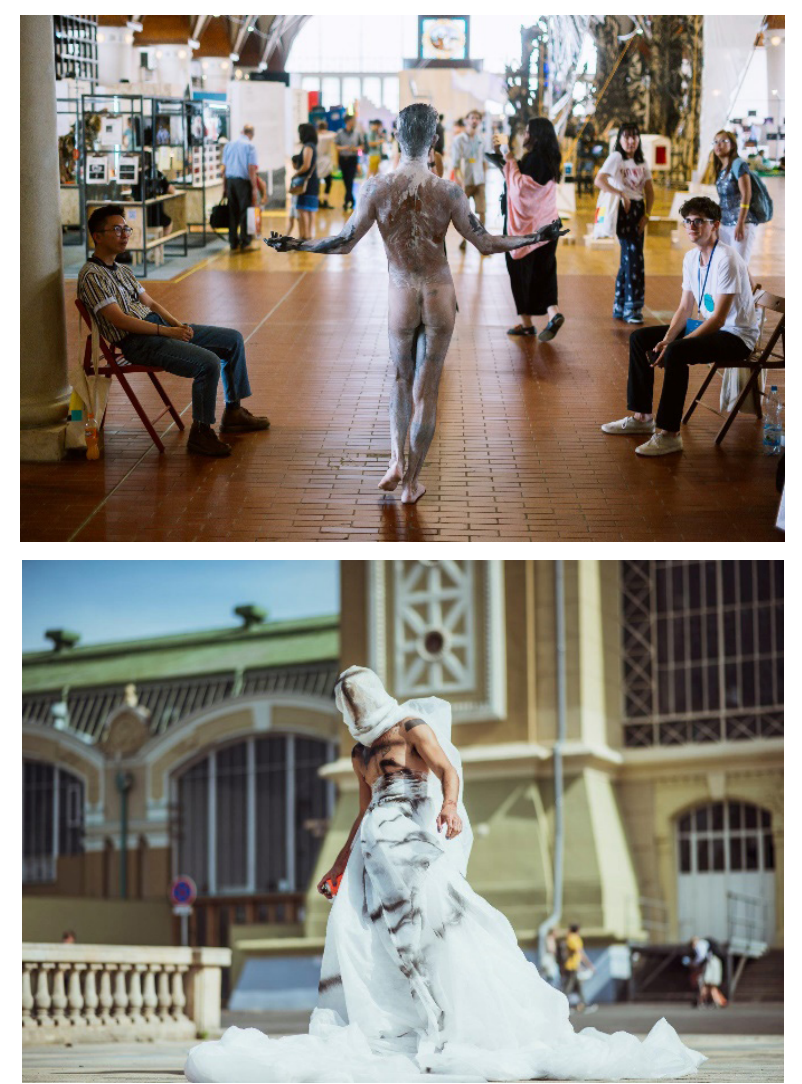

Fonte: fotos de Jan Hromádko (2019) e Eva Neuzilova (2019), respectivamente.
A transitoriedade da Mostra permite explorar diversas possibilidades de interação e reação no contexto da $P Q$. A cada dia um percurso, direção e objetivo traçados. O grupo se desloca em fila, como um bloco ou abre-alas, reconfigurando territórios em lugares neutros, visitando e interagindo com outros países e regiões, migrando, ocupando outros territórios. Corpo e placa tornados um corpo único. A placa/cavalete desenhada à proporção do corpo humano, identificada como corpo móvel, impermanente; o corpo por sua vez, identificado como suporte vivo, interativo, móvel.

Experiências marcantes e significativas acontecem a cada deslocamento, uma em especial, na proposta de depositar as placas/cavaletes em outros territórios (espaços expositivos de outros países e regiões) e subtrair o corpo, deixando apenas as placas autoportantes como corpos em si e provocando reações diversas, notadamente de desconforto à permanência do corpo que, em vários casos, foram removidos para fora dos territórios ocupados. Configura-se, portanto, uma divergência de tolerância à presença quando um corpo imóvel em comparação à sua mesma presença como extensão de um corpo suporte e móvel. Experiências que reforçam a proposta curatorial em explorar a potência do CORPO COMO ESPAÇO, TERRITÓRIO E SUAS FRONTEIRAS. 
Figuras 4 e 5 - Mostra Nacional Brasileira no espaço dado, e fora dele ocupando outro território na PQ2019.
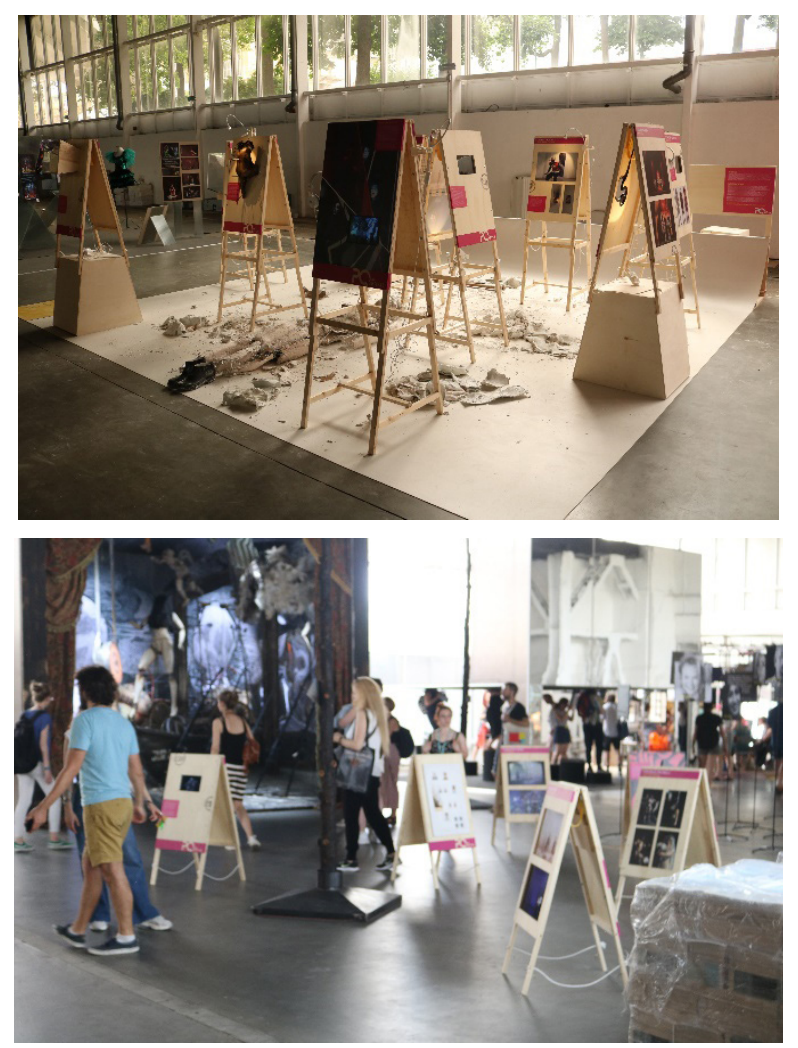

Fonte: Fotos de Calen Dawkins (2019).

Em resposta ao tema lançado pela direção artística da PQ2019 baseado na imagem da Triga - os três cavalos como forças, motores conduzidos pela figura humana e em metáfora aos pilares do processo criativo do artista do espaço e desenho da cena - Memória, Imaginação e Transformação, a participação do Brasil na PQ2019 prefere provocar para a continuidade em explorar as possibilidades renovadoras e transformadoras que o palco global da $P Q$ oferece. A transformação está, portanto, em experimentar formas inéditas de estar na $P Q$ como indivíduo, como coletivo, como território aberto, de forma ousada, mutável, explorando limites.
Figuras 6 e 7 - Performances: Apresamento (esq.) e Desaparecido (dir.) para a Mostra Nacional do Brasil / Intersecções, na PQ2019.
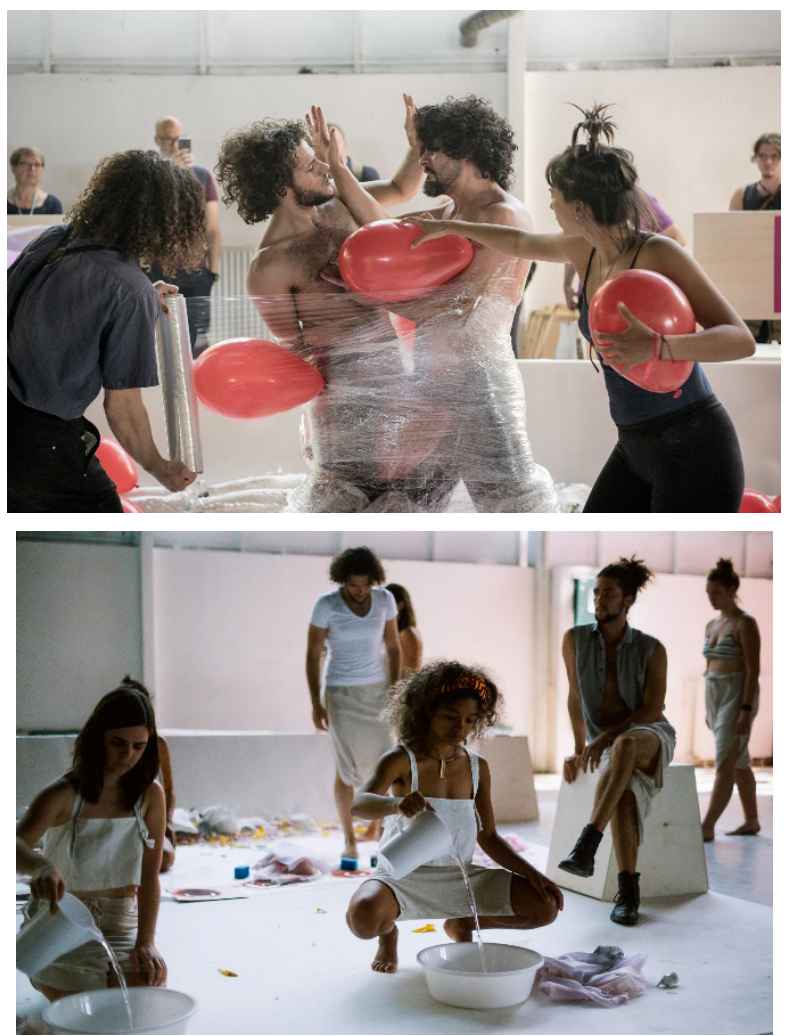

Fonte: fotos de Alžběta Jungrová (2019) e Jan Hromádko (2019), respectivamente.

\section{Proposições e diretrizes da PQ2019}

A proposta temática da PQ2019 em destacar os pilares da Memória, Imaginação e Transformação pode ser interpretada como etapas de um processo criativo deflagrado pelo artista que desenha o espaço e a cena; por outro lado, a direção artística, ao sistematizar estas etapas, relacionando-as a grupos distintos, abre precedente para definir limites, territorializar e, possivelmente, reforçar certas hierarquias ao endereçar o campo da memória à Mostra Fragmentos - dedicada a consagrados artistas, o campo da imaginação ao trabalho dos estudantes e a potência de transformação identificada apenas com a produção profissional. Além do tema proposto, a definição espacial e geográfica do evento também impacta diretamente 
sobre as diretrizes a serem apontadas pela $P Q$ em seu posicionamento estético, político e social; reflete sobretudo nas propostas conceituais dos países participantes. A opção pelo retorno ao Palácio Industrial Výstaviště como sede da PQ2019, onde esteve pela última vez em 2007, traz à tona, inevitavelmente, significados, intencionais ou não. Para alguns um lugar de conforto, e reconhecimento, evocando certa nostalgia; para outros um paralelo aos movimentos políticos globais assistidos diariamente em direção ao retrocesso, ao conservadorismo e, para aqueles que vivenciam a $P Q$ pela primeira vez outras diversas leituras, nas quais por vezes a localização geográfica não parece tão relevante. Ao retornar à antiga sede, a PQ distancia-se de certa maneira do ponto de contato com a localidade que lhe dá nome; ainda que no passado não houvesse interesse ou relevância sobre este aspecto, após a edição de 2015 torna-se inevitável este refletir sobre esta questão.

A PQ2019 desdobra-se em diversos espaços e, ao redesenhar uma cartografia imaginária para esta $14^{a}$ edição, pode-se pensar o espaço global da cidade de Praga, o espaço geográfico do Palácio Industrial Výstaviště como um continente isolado e a constituição de espaços territorializados em dois planos: demarcado por áreas iguais de $25 \mathrm{~m}^{2}$ e demarcado também pela proposição conceitual do tema.

Considerando ainda a relevância de encontros e debates durante a preparação do evento, esta edição registra o Simpósio de 50 anos da PQ, em 2017 , celebrando o tema Fronteiras Porosas, inspirador que colabora para refletir e discutir o mundo e as interrelações em diversos contextos e camadas sociais, políticas e geográficas, inclusive no acontecimento da $P Q$. Parecia sinalizar uma tendência por explorar os pontos de contato e o convite a romper com barreiras e hierarquias, o que de alguma maneira não transparece, tampouco é tornado presente em 2019.

Na prática, entretanto, através da experiência ao longo de várias edições do evento, fica evidente que não é unânime a adesão dos curadores dos países e regiões, participantes da Quadrienal de
Praga, ao diálogo com o tema ou conceito proposto, permitindo emergir outras leituras e respostas. A $P Q$ resulta, portanto, de uma combinação entre as diversas inquietudes e, também, da ausência delas. Citando, como exemplo, a participação do Brasil na Mostra dos Estudantes que entrelaça dois dos três conceitos, operando entre a imaginação e a transformação. Ao passo que, na Mostra Nacional rompe definitivamente com os limites territoriais físicos e conceituais, explorando as possibilidades de existir nas incertezas e impermanências dos espaços territorializados e geográficos da $P Q$.

Outros países visivelmente, na corrente da PQ2015, demonstram continuado interesse em explorar o papel sócio-político do espaço e desenho da cena. Este Edifício Realmente Fala, proposta curatorial da República da Macedônia do Norte, premiada com a Triga de Ouro, reforça o desejo em apontar para um resultado que apresenta uma narrativa política, ativada através do desenho do espaço e da elaboração cênica.

A exposição é um trabalho
colaborativo apresentado em
camadas múltiplas que reúne
diversas formas de cenografia:
espaço, palco, exposição, me-
mória, comunidade e comuni-
cação. Demonstra como a per-
formance ativa um espaço de
exposição, como o design ins-
tiga a narrativa e a cenografia
torna-se ativismo dentro e fora
do contexto político. (PQ2019
texto do júri, 2019 , tradução
nossa. Documento eletrônico).

O júri, ao premiar esta proposta, revela certa convergência com a PQ2015. Lembrando que a Mostra da Estônia, premiada com a Triga de Ouro, também se destacava por "apresentar uma manifestação fictícia que, ao longo de dois meses, tornou-se uma força política relevante (...). O uso da cenografia de maneira que contribui para o desenvolvimento de formas de combinar a narrativa com o design da performance". (PQ2015, texto do site, 2015, tradução nossa. Documento eletrônico). 


\section{Considerações finais}

Ao destacar esta ou aquela proposta, a PQ valida e aponta diretrizes em concordância com o que estas apresentam e significam. A performance Este Edifício Realmente Fala apoia-se no desenho e transformação de um espaço mas, sobretudo, está pautada pelo texto; a narrativa textual está em primeiro plano. Neste contexto, emerge o questionamento sobre o papel da Quadrienal de Praga do Espaço e Desenho da Cena, sua influência como referência global e o que ela valida, ao reafirmar formas de narrativas relevantes na cena teatral contemporânea.

Estará a narrativa necessariamente atrelada ao textual? Se, o discurso narrativo e a palavra se reafirmam no âmbito da Quadrienal de Praga do Espaço e Desenho da Cena, em que medida a PQ encoraja a cenografia como elemento narrativo em si, autossuficiente, capaz de existir independente e destacado em primeiro plano. O que considerar como diretriz sobre o papel e lugar do artista do espaço e desenho da cena contemporânea?

Entendendo a PQ como um lugar de convergência, exposição e reflexão sobre as diversas práticas, modos de produção, de pensamento e conhecimento, a sua construção e desenvolvimento acontecem a partir da presença, participação e engajamento daqueles interessados no campo do Espaço e Desenho da Cena. Convido, portanto, a pensarmos em uma estrutura menos hierárquica e mais horizontal para refletirmos e construirmos caminhos que atendam e deem subsídio às diversas inquietudes dos artistas no que diz respeito ao seu papel e lugar na cena contemporânea no contexto local e/ou global no qual atua.

Talvez ainda demore para que a organização da $P Q$ proponha um formato de Fórum permanente, mas podemos iniciar esta proposta localmente, a exemplo da proposta curatorial do Brasil para a edição da PQ2019 que, ao longo de dois anos promoveu encontros regulares, informativos, eventos, e que mantém em espaço compartilhado, público e digital, o registro destas ações, das propostas curatoriais para cada segmento, a relação dos artistas participantes através da plataforma digital PQBrasil (www.pqbrasil.org). Neste mesmo espaço, procura alimentar informações de referência histórica e conceituais sobre as participações anteriores do Brasil na Quadrienal de Praga. Ações permanentes demandam esforço também continuado, entretanto, percebe-se um esvaziamento - local e global - no período que sucede o evento da Quadrienal de Praga, dificultando assim o debate e compartilhamento de reflexões sobre as possíveis diretrizes apontadas e alcançadas pelo evento, que possam nos alimentar, artistas e curadores, durante esta lacuna de quatro anos até o próximo encontro, inclusive para que seja este um lugar de constante desenvolvimento e não de estagnação ou retrocesso. Sobretudo, neste momento, em que se faz tão importante combater o retrocesso.

O trabalho curatorial é constituído pela experiência, conhecimento, pesquisa e percepção do mundo ao redor, mas também por uma dose de instinto assim como quando desenhamos, talvez este também possa ser definido como uma forma de percepção. Após esta experiência curatorial, conceitos definidos, projeto expositivo e presença no evento, deparo-me com o pensamento de um grande artista que admiro profundamente e que com certeza estava na minha bagagem quando da formulação desta proposta, mas que apenas reconheci, com enorme satisfação, meses mais tarde ao visitar sua exposição na Royal Academy em Londres, em cartaz de outubro a dezembro de 2019: Antony Gormley. Ele trabalha há mais de 20 anos sobre o tema do corpo e para o texto de sua exposição ele afirma que, para ele hoje, "o corpo é mais um lugar do que um objeto: o corpo inserido no espaço e o corpo como espaço". (GORMLEY, 2019. Documento eletrônico).

Este encontro com Gormley proporciona um diálogo distinto e enriquecedor, diferente da experiência na Quadrienal de Praga 2019. Entretanto, sem o evento da $P Q$ e o projeto desenvolvido para 
este fim, este encontro com Gormley certamente não estabeleceria o mesmo diálogo e impacto. Neste sentido, a reflexão hoje, como curadora, com experiência em ambos os lados da $P Q$, está na sua ação externa, as demais parcerias e diálogos que é capaz de estabelecer para além do Palácio Industrial Výstaviště e da cidade de Praga, a fim de identificar outros possíveis pontos de convergência, encontro e reflexão da comunidade do Espaço e Desenho da Cena Contemporânea.

\section{Referências}

ARONSON, Arnold; PARIZKOVA, Daniela. Exhibition on the Stage: Reflections on the 2007 Prague Quadrennial. Praga: Institut umeni/Divadelni ustav, 2008.

COHEN, Miriam Aby. PQ Brasil 2019: catálogo da representação brasileira na Quadrienal de Praga 2019. Rio de Janeiro, PQBrasil, 2019.

GORMLEY, Antony. Website do artista. Disponível em: http://www.antonygormley.com/sculpture/itemview/id/266. 2019.

KANT, Immanuel. A crítica da razão pura. Lisboa: Fundação Calouste Gulbenkian, 1989.

LOTKER, Sodja. Website da Quadrienal de Praga. Disponível em: http://2015.pq.cz.s3.amazonaws. com/www/en/program/intro.html. 2015.

PQ2015. Texto do website. Disponível em: http://2015. pq.cz.s3.amazonaws.com/www/en/press/2015/6/23/ prestigious-golden-triga-prague-quadrennial-2015-goes-estonia.html. 2015.

PQ2019. Texto do Júri. Disponível em: https://www. pq.cz/awards-winners. 2019.

Recebido: 21/11/2019

Aprovado: 12/03/2020 